\title{
Hauke Delfs
}

\section{Komplementäre Integration}

\author{
Grundlegung und Konstitutionalisierung des Europarechts im Kontext
}

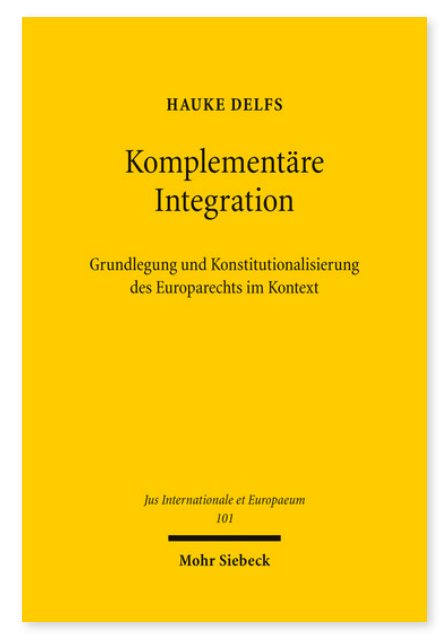

2015. XXVII, 458 Seiten. JusIntEu 101

ISBN 978-3-16-153730-1

DOI 10.1628/978-3-16-153730-1

eBook PDF 104,00€

ISBN 978-3-16-153723-3

fadengeheftete Broschur 104,00€
Das Europarecht der Gegenwart steht in einem eigentümlichen Verhältnis zu seiner Geschichte. Die Europäischen Gemeinschaften sollten eine neue Rechtsordnung verkörpern, die Funktionslogik des klassischen Völkerrechts abstreifen und einen bewussten Gegenentwurf zu staatlichem Recht darstellen. Die zukunftsgerichtete Offenheit der europäischen Integration ermöglichte zugleich einen Fortschritt im Recht, der sich autonom von mitgliedstaatlichen Bindungen vollzogen zu haben scheint. Die Entstehungsgeschichte der Europäischen Verträge wurde deshalb mit der Zeit immer weniger beachtet, während rechtshistorische Perspektiven heute die Rechtsprechung des EuGH in den Mittelpunkt rücken. Hauke Delfs unternimmt eine aus historischen Quellen gearbeitete Rechtsgeschichte der europäischen Integration und stellt dem politischen Integrationsprozess dessen normative Entwicklung gegenüber. Dieser Zugang zeichnet ein differenziertes Bild von der Entstehung der europäischen Rechtsordnung und erlaubt zugleich eine historisch informierte Diskussion aktueller Fragestellungen der europäischen Integration.

Für die Arbeit wurde Hauke Delfs von der Juristischen Fakultät der Universität Göttingen und der Juristischen Gesellschaft zu Kassel mit dem Preis für die beste Dissertation 2014 ausgezeichnet.

Hauke Delfs Geboren 1982; Studium der Rechtswissenschaften in Göttingen; wissenschaftliche Hilfskraft am Institut für Völker- und Europarecht der Universität Göttingen; seit Mai 2014 Referendariat in Berlin.

Jetzt bestellen:

https://mohrsiebeck.com/buch/komplementaere-integration-9783161537301?no_cache=1

order@mohrsiebeck.com

Telefon: +49 (0)7071-923-17

Telefax: $+49(0) 7071-51104$ 